\title{
Improvement in radiosensitivity using small interfering RNA targeting p53R2 in esophageal squamous cell carcinoma
}

\author{
NAOYA YOKOMAKURA ${ }^{1}$, SHOJI NATSUGOE $^{1}$, HIROSHI OKUMURA $^{1}$, \\ RYUJI IKEDA ${ }^{2}$, YASUTO UCHIKADO ${ }^{1}$, YUKO MATAKI ${ }^{1}$, HIROYUKI TAKATORI ${ }^{1}$, \\ MASATAKA MATSUMOTO ${ }^{1}$, TETSUHIRO OWAKI ${ }^{1}$, SUMIYA ISHIGAMI $^{1}$ and TAKASHI AIKOU ${ }^{1}$ \\ Departments of ${ }^{1}$ Surgical Oncology and Digestive Surgery; ${ }^{2}$ Clinical Pharmacy and Pharmacology, Graduate \\ School of Medicine, Kagoshima University, 8-35-1 Sakuragaoka, Kagoshima 890-8520, Japan
}

Received April 4, 2007; Accepted May 2, 2007

\begin{abstract}
Chemoradiation therapy (CRT), a combination of $\mathrm{X}$-ray irradiation and anticancer agents as a radiosensitizer, has been found to be an effective treatment for esophageal cancer and has been linked to p53 genetics. The p53 gene family regulates cell-cycle arrest, apoptosis and DNA damage repair. A recently identified ribonucleotide reductase, p53R2, is directly regulated by p53 in the supply of nucleotides for repairing damaged DNA. In the present study, we investigated the improvement in radiosensitivity of human esophageal squamous cell carcinoma (ESCC) cell lines using p53R2 small interfering RNA (siRNA). p53R2 expression in ESCC cells (TE-8) with or without transfection of p53R2 siRNA was examined by Western blot analysis and reverse transcriptionpolymerase chain reaction (RT-PCR). The radiosensitivity of TE-8 cells was also measured by cell survival assay. In addition, we investigated the relationship between the expression of p53R2 mRNA in the biopsy specimens of untreated primary tumors and the efficacy of CRT, using RT-PCR. The expression of p53R2 was amplified after X-ray irradiation (14 Gy) and diminished after X-ray irradiation following the transfection of p53R2 siRNA in TE-8 cells. The radiosensitivity of the TE- 8 cells significantly improved following the transfection of p53R2 siRNA. In the clinical study, a significantly lower p53R2 mRNA expression was detected in the effective response cases. We demonstrated that $\mathrm{p} 53 \mathrm{R} 2$ is associated with the radiosensitivity of ESCC cell lines, and that $\mathrm{p} 53 \mathrm{R} 2$ expression is reduced after $\mathrm{X}$-ray irradiation following the transfection of p53R2 siRNA. This protocol could potentially improve the efficacy of radiation therapy.
\end{abstract}

Correspondence to: Dr Naoya Yokomakura, Department of Surgical Oncology and Digestive Surgery, Graduate School of Medicine, Kagoshima University, 8-35-1 Sakuragaoka, Kagoshima 890-8520, Japan

E-mail: makur@m3.kufm.kagoshima-u.ac.jp

Key words: p53R2, small interfering RNA, radiosensitivity, esophageal squamous cell carcinoma

\section{Introduction}

Esophageal squamous cell carcinoma (ESCC) is a highly malignant disease and various types of aggressive therapy are used as treatment. Since the 1980s, chemoradiation therapy (CRT), a combination of X-ray irradiation and anticancer agents as a radiosensitizer, has been frequently used for tumor down-staging, increasing the resection rate, and possibly improving survival $(1,2)$. The most widely adopted CRT regimen for ESCC consists of daily X-ray irradiation plus 5fluorouracil (5-FU) and cisplatin (CDDP) infusion. Since some patients respond well to CRT while others do not, it is important to establish methods of predicting the response to CRT prior to treatment $(3,4)$ and of improving the radiosensitivity of non-responders.

The ribonucleotide reductase (RR) small subunit 2 homologue, p53R2, has been shown to be directly regulated by 553 in the supply of nucleotides for the repair of damaged DNA caused by various genotoxic stresses, including UV light or $\gamma$-irradiation (5). DNA synthesis in the cells arrested in the $\mathrm{G}_{1}$ and $\mathrm{G}_{2}$ phase after DNA damage is mediated through the RR activity of p53R2, and the inactivation of p53R2 could result in the activation of a p53-dependent apoptotic pathway, eliminating the cells containing un-repaired DNA (6). Clinically, we have already reported that the positive expression of the $\mathrm{p} 53 \mathrm{R} 2$ protein in tumor samples is associated with a poor response to CRT in ESCC (4). Taken together with previous studies, we hypothesized that the knockdown of p53R2 would improve the radiosensitivity in ESCC.

RNA interference (RNAi) is a newly discovered method for the knockdown of a specific target molecule by the introduction of the cognate double-stranded small interfering RNAs (siRNAs). The mediators of sequence-specific mRNA degradation are 21- and 22-nucleotide-long siRNAs generated by the ribonuclease III cleavage from longer dsRNAs (7-11). RNAi has become an indispensable tool in the study of the regulation of target gene expression and function in vitro $(12,13)$.

In the present study, we assessed whether p53R2 is a molecular target for gene therapy, and whether a better therapeutic effect could be obtained by the suppression of $\mathrm{p} 53 \mathrm{R} 2$ using p53R2 siRNA transfection in the CRT treatment of ESCC. 


\section{Materials and methods}

Cell lines and culture. The human ESCC cell lines, TE-6, TE-8 and TE-9, were obtained from the Cell Resource Center for the Biomedical Research Institute of Development, Aging and Cancer (Tohoku University, Sendai, Japan). They were cultured in RPMI-1640 (Nissui Pharmaceutical Co., Ltd., Tokyo, Japan) supplemented with antibiotics (100 units/ml penicillin and $100 \mu \mathrm{g} / \mathrm{ml}$ streptomycin), and $10 \%$ fetal bovine serum at $37^{\circ} \mathrm{C}$ in a humidified atmosphere of $5 \% \mathrm{CO}_{2}$ in air.

$X$-ray irradiation. The cell lines were cultured $\left(37^{\circ} \mathrm{C}, 5 \%\right.$ $\mathrm{CO}_{2}$ ) in a conditioned medium until the cells reached $\sim 80 \%$ confluence on 100-mm dishes (CellStar ${ }^{\circledR}$; Greiner Bio-one, Kremsmünster, Austria) and then treated with 14 Gy X-ray irradiation (150 kV and $5 \mathrm{~mA}$ ) using an X-ray generator (MBR-1505R2; Hitachi Medical Co., Tokyo, Japan).

siRNA preparation and transfection. siRNA duplexes were synthesized using the silencer ${ }^{\mathrm{TM}}$ siRNA Construction Kit (Ambion Inc., Austin, TX, USA). The sequences of the p53R2 oligonucleotides were synthesized by in vitro transcription. The 21-nucleotide p53R2 siRNA sense strand (5'UGUAUAAACAGGCACAGGCUU-3') starts at nucleotide 164 downstream of the AUG start codon of the p53R2 CDS (GenBank accession No. NM_015713). The p53R2 siRNA antisense strand was 5'-GCCUGUGCCUGUUUAUACAUU3'. siRNA ( $30 \mathrm{nM}$ ) was introduced into the TE- 8 cells using Lipofectamine 2000 Reagent (Invitrogen Corp., Carlsbad, CA, USA) according to the manufacturer's instructions. The cells were treated by X-ray irradiation at $24 \mathrm{~h}$ posttransfection and analyzed by Western blotting, reverse transcription-polymerase chain reaction (RT-PCR) and confocal microscopy at $24 \mathrm{~h}$ post-X-ray irradiation.

Preparation of cell lysates and Western blot analysis. The cells were washed with PBS and scraped into PBS containing a 10-fold dilution of RIPA Lysis Buffer (Lake Placid, NY, USA) and $1 \mathrm{mM} p$-amidinophenyl methanesulfonyl fluoride hydrochloride (Wako, Osaka, Japan). The lysate was passed through a 21-gauge needle to shear the DNA, incubated for $30 \mathrm{~min}$ on ice, and centrifuged at $15,000 \times \mathrm{g}$ for $20 \mathrm{~min}$ at $4^{\circ} \mathrm{C}$. The supernatant was used as the total cell lysate. Cell lysates (100 $\mu \mathrm{g}$ protein/aliquot) were separated by SDSpolyacrylamide gel electrophoresis and then transferred onto polyvinylidene difluoride membranes (Immobilon-P, Millipore, Bedford, MA, USA) in transfer buffer [48 mM Tris, $39 \mathrm{mM}$ glycine ( $\mathrm{pH}$ 9.2) containing $20 \%(\mathrm{v} / \mathrm{v})$ methanol] at $20 \mathrm{~V}$ for $30 \mathrm{~min}$ at room temperature. To block nonspecific binding, the blots were preincubated for $1 \mathrm{~h}$ at room temperature in $3 \%$ skimmed milk in a washing buffer $[0.35 \mathrm{M} \mathrm{NaCl}, 10 \mathrm{mM}$ Tris- $\mathrm{HCl}$ ( $\mathrm{pH} 8.0), 0.05 \%$ Tween-20]. The blots were then incubated at $4^{\circ} \mathrm{C}$ for $8 \mathrm{~h}$ with p53 antibody (1:1250), p53R2 antibody (1:1000), or ß-actin antibody (ab8226; Abcam Ltd., Cambridge, UK) (1:5000), followed by washing with the washing buffer and incubation for $1 \mathrm{~h}$ at room temperature with horseradish peroxidase-conjugated secondary antibody. Antibody binding was visualized using the ECL Western blotting detection reagents and analysis system (Amersham Biosciences Corp., Piscataway, NJ, USA). MCF-7 cells were used as the positive control for the expression of p53R2, and $ß$-actin immunoblotting was performed as the loading control.

Cell survival assay. The cell lines were cultured on 6-well plates (Iwaki Microplate; Iwaki Glass Co., Funahashi, Japan) in a conditioned medium at a density of $1 \times 10^{5}$ cells. After incubation for $24 \mathrm{~h}\left(37^{\circ} \mathrm{C}, 5 \% \mathrm{CO}_{2}\right)$, X-ray irradiation $(0,5$, $10,15,20,25,30,35,40 \mathrm{~Gy})$ was administered to the plates. On the 5th day after X-ray irradiation, the plates were rinsed with PBS to wash out the remaining conditioned medium, and then Calcein-AM solution (Dojindo Laboratories, Kumamoto, Japan) at a concentration of $2 \mu \mathrm{g} / \mathrm{ml}$ in PBS (500-fold dilution), was added to the plates. After a 60 -min incubation $\left(37^{\circ} \mathrm{C}, 5 \% \mathrm{CO}_{2}\right)$, Calcein-AM solution was exchanged with PBS to reduce the background fluorescence. The fluorescence in the plates was measured immediately using a Cytofluor ${ }^{\circledR} 4000$ Fluorescence Multi-Well Plate Reader (Applied Biosystems, Foster City, CA, USA) at an excitation wavelength of $485 \mathrm{~nm}$ and an emission wavelength of $530 \mathrm{~nm}$ (gain of 50).

Confocal laser scanning microscopy. The cells were cultured on 4-well glass slides (Lab-Tek ${ }^{\mathrm{TM}}$ Chamber Slide ${ }^{\mathrm{TM}}$ System; Nalge Nunc International, Rochester, NY, USA) in a conditioned medium at a density of $1 \times 10^{5}$ cells. After 48-h incubation $\left(37^{\circ} \mathrm{C}, 5 \% \mathrm{CO}_{2}\right)$, the cells were washed with PBS and fixed with $3.7 \%$ buffered formaldehyde for $30 \mathrm{~min}$. Thereafter, the cells were rinsed with PBS and fixed in 100\% methanol for $10 \mathrm{~min}$. After washing with PBS, the cells were blocked by treating with $3 \%$ skimmed milk for $30 \mathrm{~min}$, after which the blocked cells were incubated for another hour in $3 \%$ skimmed milk containing p53R2 antibody (100-fold dilution). After washing with PBS, the cells were incubated with the secondary antibody (FITC-Rabbit Anti-Goat IgG Conjugate; Zymed ${ }^{\circledR}$ Laboratories Inc., San Francisco, CA, USA) and 4',6-diamidino-2-phenylindole dihydrochloride (DAPI, Nucleic Acid Stain; Invitrogen Corp.) for $30 \mathrm{~min}$ under light shielding. The glass slides were washed with PBS and mounted with a coverslip using mounting medium (Perma Fluor; Thermo Electron Corporation, Woburn, MA, USA). All treatments were performed at room temperature. Images were acquired using a confocal microscope (FV500; Olympus Corporation, Tokyo, Japan) with 405 and $488 \mathrm{~nm}$ laser illumination.

Total RNA extraction and complementary DNA (cDNA) synthesis. RNA was extracted from the TE- 8 cells treated by no treatment, X-ray irradiation (14 Gy), or p53R2 siRNA transfection + $14 \mathrm{~Gy}$, using guanidium-isothiocyanatephenol-chloroform (Isogen; Nippon Gene Co., Tokyo, Japan) according to the manufacturer's instructions. The concentration of total RNA was determined by absorption measurement at optical densities of 260 and $280 \mathrm{~nm}$ using a UV-visible spectrophotometer (BioSpec-1600; Shimadzu Biotech, Kyoto, Japan). Prior to the synthesis of cDNA, $1 \mu 1$ deoxyribonuclease I [DNase I (Amplification Grade); Invitrogen Corp.] and $1 \mu 1$ 10x reaction buffer were added to each $1 \mu \mathrm{g}$ total RNA in autoclaved water (diethylpyrocarbonate-treated water; Nippon Gene Co.) in a total volume of $10 \mu \mathrm{l}$. The reaction mixture was incubated for $10 \mathrm{~min}$ at 
$37^{\circ} \mathrm{C}$. Next, $1 \mu 125 \mathrm{mM}$ EDTA was added. The $11 \mu 1$ reaction mixture was incubated for $10 \mathrm{~min}$ at $65^{\circ} \mathrm{C}$ and quickly chilled on ice. Next, cDNA was synthesized using a commercial kit (All Advantage RT for PCR Kit; BD Biosciences Clontech Laboratories Inc., Mountain View, CA, USA) according to the manufacturer's instructions.

RT-PCR. Amplification of p53R2 and glyceraldehydes 3phosphate dehydrogenase (GAPDH) cDNA was performed in a total volume of $30 \mu \mathrm{l}$, which included $1 \mu \mathrm{l}$ of the cDNA product sample, $0.5 \mu \mathrm{M}$ of each of the forward and reverse p53R2 and GAPDH primers, GeneAmp 10x PCR Buffer (Applied Biosystems), $0.5 \mathrm{U}$ AmpliTaq DNA polymerase (Applied Biosystems), and $25 \mathrm{mM}$ dNTP mixture (Takara Bio Inc., Otsu, Japan). The GAPDH gene served as an internal control. The oligonucleotide primers designed for the p53R2 and GAPDH genes were: p53R2 forward primer, 5'AATGAACTCATCAGCAGAGATG-3' and reverse primer, 5'-CTCGTTTCTCAAAGAAATTTGT-3'; GAPDH forward primer, 5'-TTGGTATCGTGGAAGGACTCA-3' and reverse primer, 5'-TGTCATCATATTTGGCAGGTTT-3'. The p53R2 and GAPDH amplification reactions were 35 cycles (p53R2) or 26 cycles (GAPDH) of denaturation at $94^{\circ} \mathrm{C}$ for $30 \mathrm{sec}$, annealing at $60^{\circ} \mathrm{C}(\mathrm{p} 53 \mathrm{R} 2)$ or $54^{\circ} \mathrm{C}(\mathrm{GAPDH})$ for $30 \mathrm{sec}$, and elongation at $72^{\circ} \mathrm{C}$ for $30 \mathrm{sec}$ in the GeneAmp ${ }^{\circledR}$ PCR System 9700 (Applied Biosystems). Amplified DNA fragments were electrophoresed on $2 \%$ agarose gels containing ethidium bromide with a DNA molecular weight marker for comparison.

Clinical specimens. Esophageal tumors were biopsied by endoscopy from 39 patients with advanced ESCC who received CRT at the Kagoshima University Hospital from 1999 to 2002, after all the patients received information from our Institutional Review Board and informed consent was provided. Three biopsy specimens of the primary tumor and normal epithelium were collected from each patient for histopathological diagnosis and RT-PCR. Fresh samples of tumor and normal tissue were stored in liquid nitrogen as soon as possible. The mean age was 66.5 years (range, $44-80$ years) and 38 patients were male. All 39 tumors were diagnosed as squamous cell carcinoma, and the patients underwent CRT, at a daily dose of 2 Gy, 5 days/week for 4-6 weeks. The area of radiation included the mediastinum and metastatic nodes as indicated by preoperative imaging. In the same period, low-dose chemotherapy as a radiosensitizer was performed intravenously using 2 anticancer agents: $7 \mathrm{mg} / \mathrm{m}^{2} \mathrm{CDDP}$ as a drip intravenous infusion for $2 \mathrm{~h}$ at 5 days per week for 4 weeks, and $350 \mathrm{mg} / \mathrm{m}^{2} 5-\mathrm{FU}$ as a continuous intravenous infusion for $24 \mathrm{~h}$ for 4 weeks. Of these patients, 12 patients underwent CRT followed by surgery, and 27 received CRT alone. The characteristics of the patients were evaluated based on the International Union Against Cancer tumor-nodemetastasis (TNM) classification system (14) as follows: The number of patients with $\mathrm{T} 1, \mathrm{~T} 2, \mathrm{~T} 3$, and T4 was $1,4,20$, and 14, N0 and N1 was 6 and 33, M0 and M1 was 30 and 9, respectively. All of the M1 category tumors were due to distant lymph node metastases. The response to CRT was evaluated by the findings of esophagography, esophagoscopy and computed tomography. The clinical criteria for the response to CRT were as follows (15): Complete response (CR), disappearance of the tumor and a continuous effect for more than 4 weeks; partial response (PR), a response rate over $50 \%$ and no new lesions for more than 4 weeks; no change $(\mathrm{NC})$, a response rate under $50 \%$ or progressive disease over $25 \%$ and no new lesions for more than 4 weeks; and progressive disease (PD), progressive disease over $25 \%$ or the appearance of new lesions. The CR or PR responses were considered representative of effective CRT, whereas the NC or PD responses were indicative of ineffective CRT.

Statistical analyses. The associations between groups were analyzed by the 1-way ANOVA or Student's t-test. The differences between the groups were tested with Fisher's exact probability test. A value of $\mathrm{P}<0.05$ was considered to be significant. All statistical analyses were performed using the software package JMP ${ }^{\mathrm{TM}}$ ver.5 (SAS Institute Inc., Cary, NC, USA).

\section{Results}

Expression of p53 and p53R2 protein in TE-6, TE-8 and TE-9 cells. The expression of the $\mathrm{p} 53$ and $\mathrm{p} 53 \mathrm{R} 2$ protein with or without X-ray irradiation (14 Gy) in the TE-6, TE- 8 and TE-9 cells was examined by Western blot analysis. p53 protein expression was detected in all the cell lines before X-ray irradiation, with a higher level in TE-6 (mutant p53), and lower levels in TE-9 (mutant p53) and TE-8 (wild-type p53) cells, as previously reported $(16,17)$. After X-ray irradiation, the p53 expression levels increased in all the cell lines, with the highest level in TE-6, a moderate level in TE- 8 and the lowest level in TE-9 cells (Fig. 1).

The endogenous expression of the p53R2 protein prior to $\mathrm{X}$-ray irradiation was detected at a lower level in TE-6 and TE-8 cells, but not in TE-9 cells. Following X-ray irradiation, the p53R2 expression levels increased in all the cell lines, with the highest level in TE-6, a moderate level in TE-8 and the lowest level in TE-9 cells (Fig. 1).

Radiosensitivity assay in TE-6, TE-8, TE-9 cells. The survival rate of each cell line was examined after X-ray irradiation (radiation dose range; 0-40 Gy) by the Calcein$\mathrm{AM}$ assay described in 'Materials and methods'. The $\mathrm{ED}_{50}$ of these cell lines was 30, 18.6, and 7.5 Gy for TE-6, TE-8, TE-9, respectively. TE-6, with the highest expression of the p53R2 protein, showed the lowest radiosensitivity, while TE-9, with the lowest expression of the p53R2 protein, showed the highest radiosensitivity. The survival curve of the TE- 8 cells, which showed a moderate expression of p53R2, was located between the TE-6 and TE-9 survival lines (Fig. 2).

Expression and distribution of p53R2 in TE-8 cells after siRNA transfection. The differences in $\mathrm{p} 53 \mathrm{R} 2$ expression between the TE- 8 cells that had undergone various treatments (no treatment, after X-ray irradiation, after X-ray irradiation following p53R2 siRNA transfection) were examined using Western blotting, RT-PCR and confocal laser scanning microscopy. The expression of the p53R2 protein and mRNA increased following X-ray irradiation, and decreased after X-ray irradiation following p53R2 siRNA 


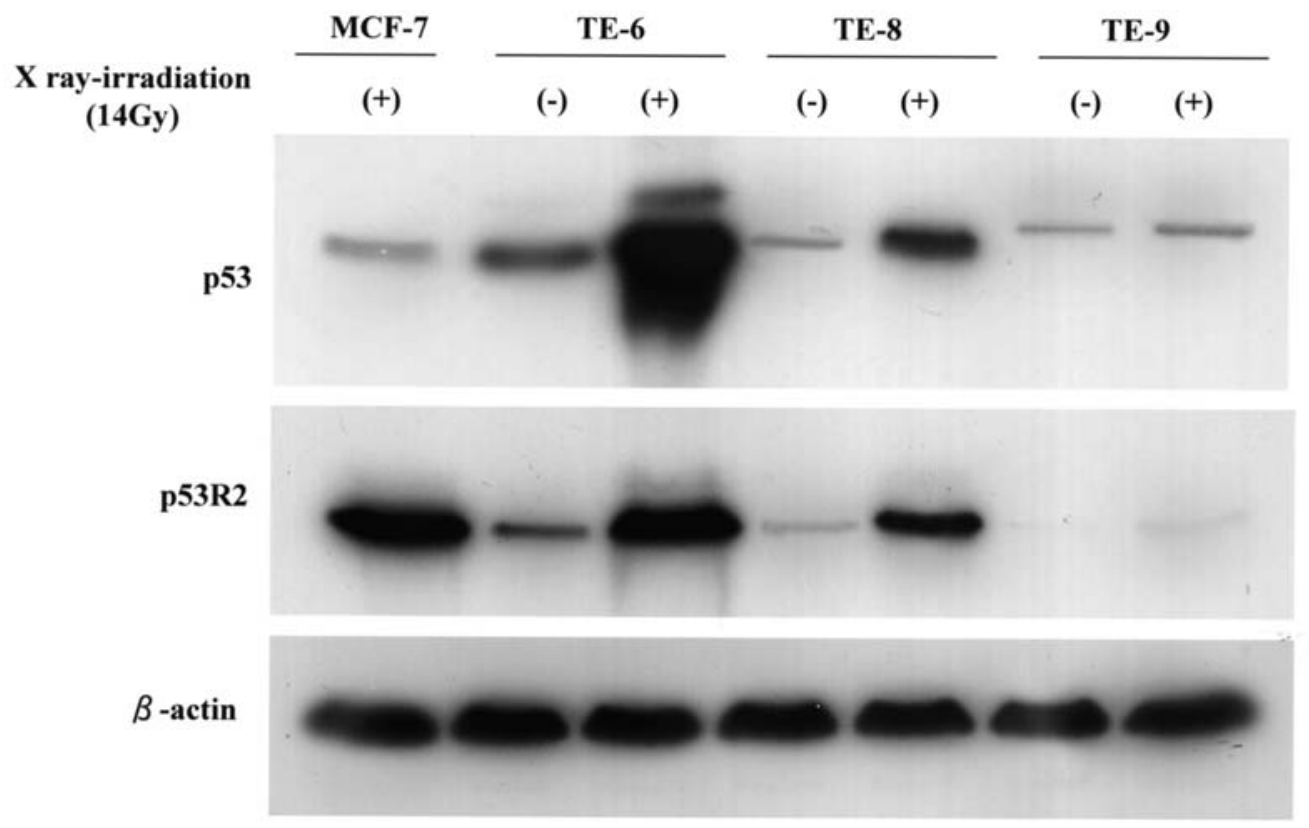

Figure 1. The expression levels of the p53 and p53R2 protein before and after X-ray irradiation (14 Gy) in the TE-6, TE-8 and TE-9 cells were examined by Western blot analysis. Total cell lysates (100 $\mu \mathrm{g}$ protein/aliquot) for the analysis of p53 and p53R2 expression were prepared and processed as described in 'Materials and methods'. MCF-7 cells were used as the positive control for the expression of p53R2, and B-actin immunoblotting was performed as the loading control.

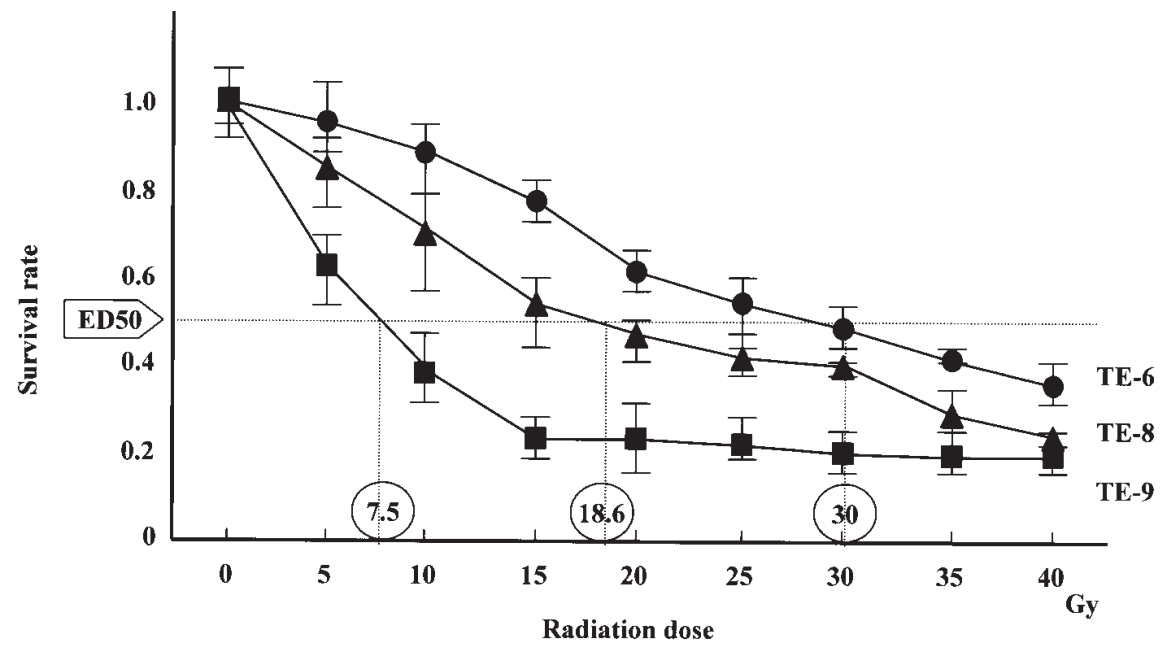

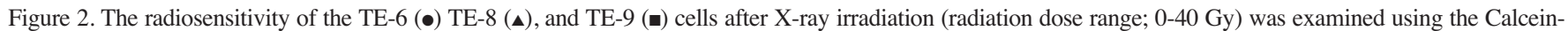
AM assay. The $\mathrm{ED}_{50}$ was $30,18.6$, and 7.5 Gy for the TE-6, TE-8, and TE-9 cells, respectively. The points represent the means of triplicate determinations; the bars represent SD.

transfection, to a lower level compared to the expression level found in the no-treatment cells (Fig. 3A and B). Confocal laser scanning microscopy detected the expression of the p53R2 protein in the cytoplasm of the no-treatment cells. Following X-ray irradiation, the expression of p53R2 increased and changed its distribution from the cytoplasm to the nucleus in these cells (Fig. 4), as previously reported (5). On the contrary, after X-ray irradiation following p53R2 siRNA transfection, the expression of p53R2 almost vanished.

Radiosensitivity assay in TE-8 cells after siRNA transfection. The survival rate of the TE- 8 cells after X-ray irradiation (radiation dose range; 0-40 Gy) with or without p53R2 siRNA transfection was also examined. The $\mathrm{ED}_{50}$ of the TE- 8 cells with or without p53R2 siRNA and with the control siRNA was $8.2,17.5$ and $18 \mathrm{~Gy}$, respectively. The radiosensitivity of the TE-8 cells significantly improved following the transfection of p53R2 siRNA compared to the radiosensitivity without p53R2 siRNA or with the control siRNA (P<0.05) (Fig. 5).

Relationship between p53R2 mRNA expression and response to $C R T$ in the clinical cases. The differences in p53R2 mRNA expression between effective and ineffective cases were examined using quantitative RT-PCR analysis with the LightCycler system. The p53R2 mRNA expression ratio was defined as p53R2 mRNA/GAPDH in the primary tumor or normal epithelium. The mean p53R2 mRNA ratio in the tumors was 0.25 (95\% confidence interval:0.09-0.40) while 


\section{A}

\begin{tabular}{|c|c|c|c|c|c|c|}
\hline \multirow[b]{2}{*}{ Treatment } & \multirow[t]{2}{*}{ MCF7 } & \multicolumn{5}{|c|}{ TE-8 } \\
\hline & & $(-)$ & $(-)$ & p53R2 siRNA & GFP siRNA & Lipofectamine \\
\hline $\begin{array}{c}\text { X ray-irradiation } \\
(14 G y)\end{array}$ & $(+)$ & $(-)$ & $(+)$ & $(+)$ & $(+)$ & $(+)$ \\
\hline p53R2 & & & & & & 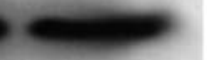 \\
\hline$\beta$-actin & & & & & & \\
\hline
\end{tabular}

B

TE-8

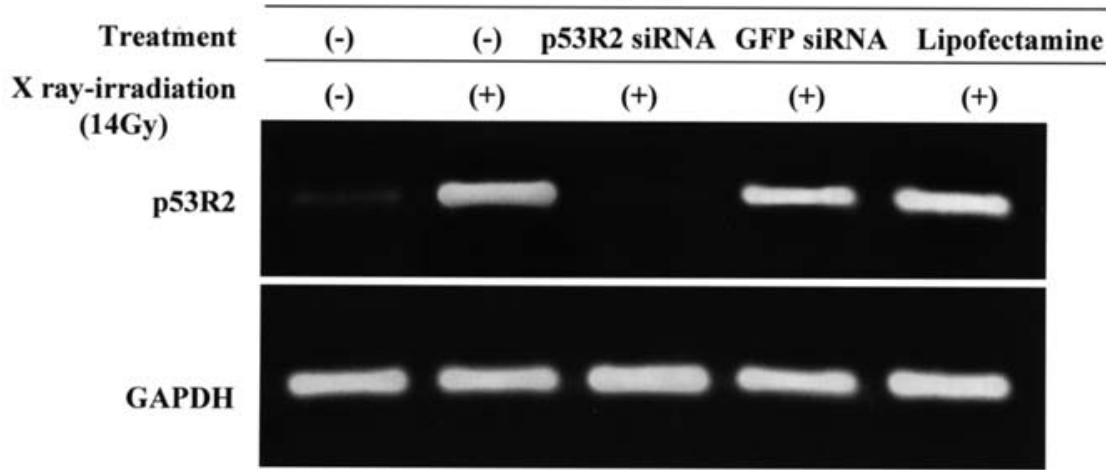

Figure 3. (A) p53R2 protein expression in the TE-8 cells (before or after X-ray irradiation without treatment, after X-ray irradiation following p53R2 siRNA transfection, GFP siRNA transfection, and Lipofectamine addition) and in the MCF-7 cells after X-ray irradiation as the positive control was examined by Western blotting. (B) The p53R2 mRNA expression in the TE-8 cells (before or after X-ray irradiation without treatment, after X-ray irradiation following p53R2 siRNA transfection, GFP siRNA transfection, and Lipofectamine addition) was examined by reverse transcription-polymerase chain reaction analysis.

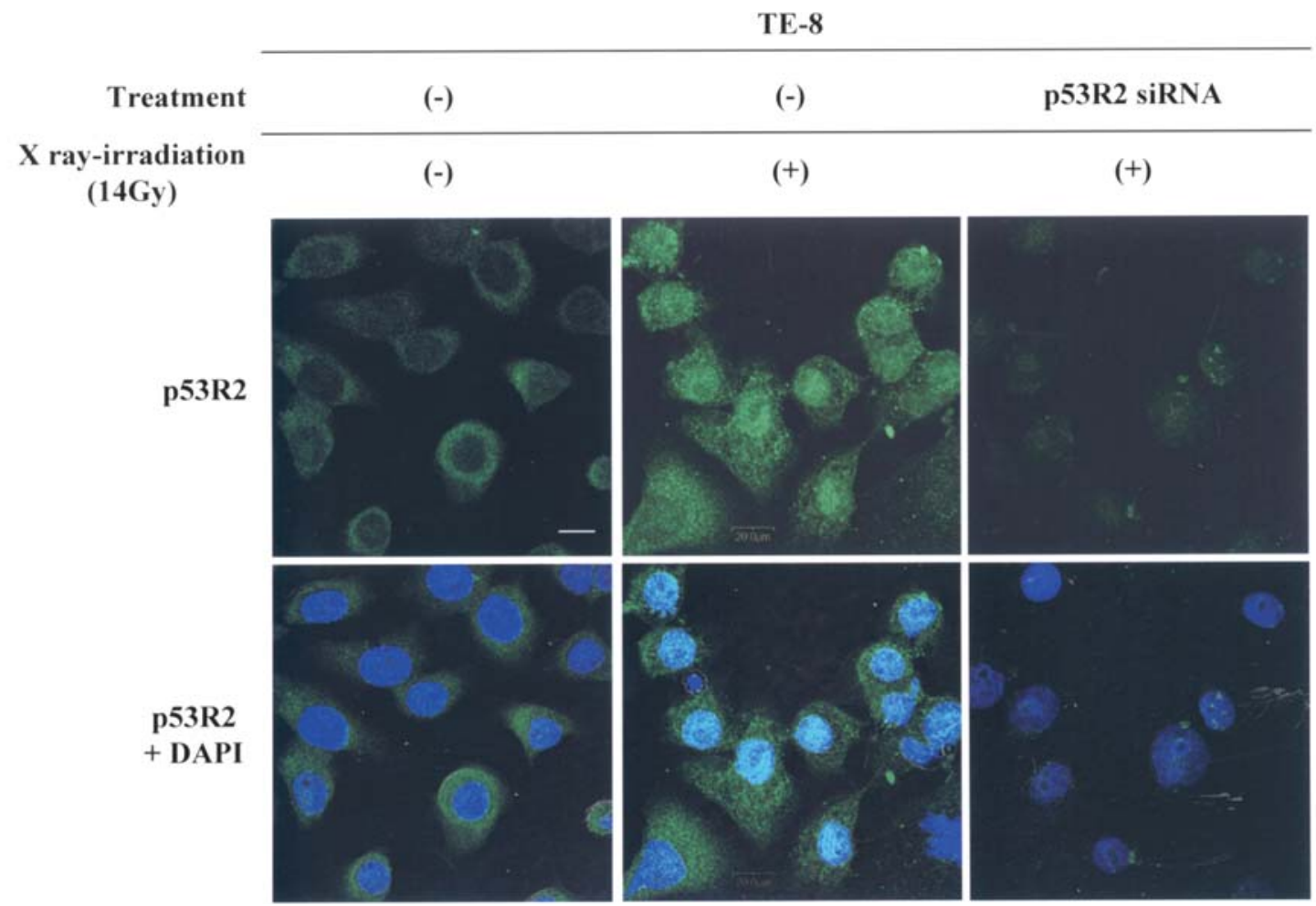

Figure 4. Cellular localization of the p53R2 protein in the TE-8 cells (before or after X-ray irradiation without treatment, after X-ray irradiation following p53R2 siRNA transfection) was examined by confocal laser scanning microscopy. Cell nuclei were stained with 4',6-diamidino-2-phenylindole dihydrochloride. Scale bar, $20 \mu \mathrm{m}$. 


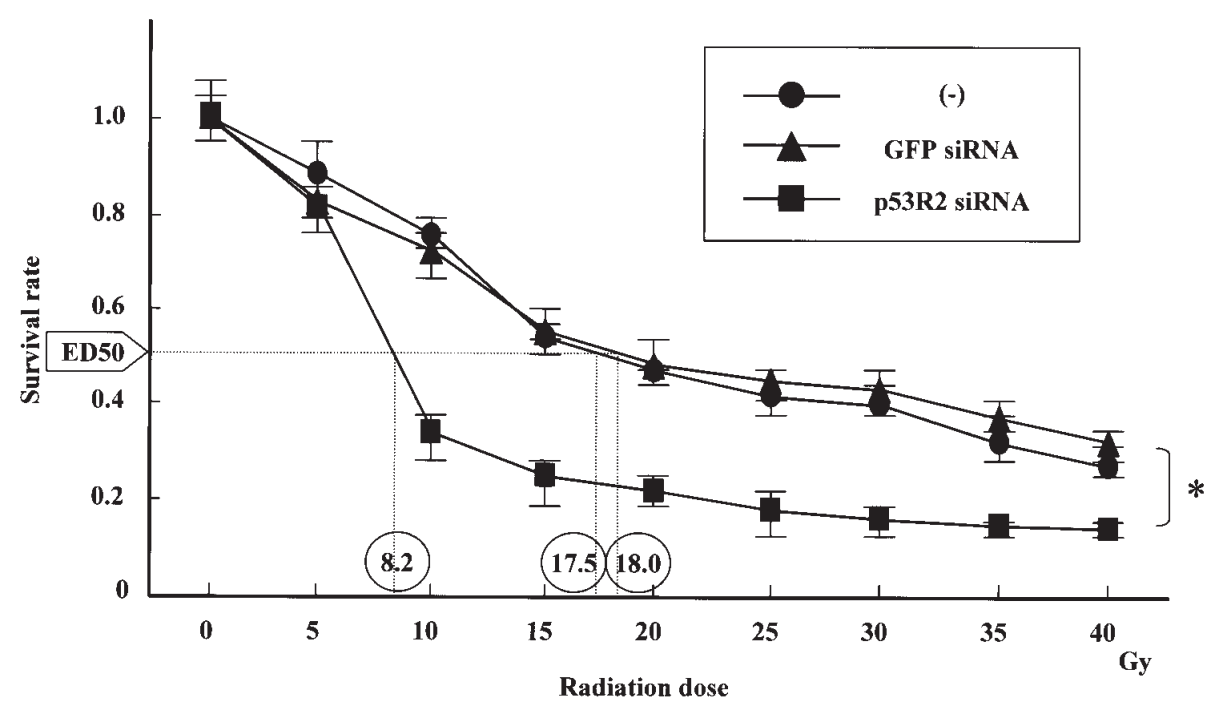

Figure 5. The radiosensitivity of the TE-8 cells after X-ray irradiation (radiation dose range; 0-40 Gy) with no treatment, GFP siRNA transfection, and p53R2 siRNA transfection was examined using the Calcein-AM assay. The $\mathrm{ED}_{50}$ was $18 \mathrm{~Gy}$ for the no-treatment cells, 17.5 Gy for the GFP siRNA transfected cells and $8.2 \mathrm{~Gy}$ for the p53R2 siRNA transfected cells. The points represent the means of triplicate determinations; the bars represent $\mathrm{SD} .{ }^{*} \mathrm{P}<0.05$.

Table I. p53R2 mRNA expression and response to CRT in ESCC.

\section{Effect of CRT}

Effective Ineffective P-value

\begin{tabular}{llll}
\hline High p53R2 mRNA ratio & 2 & 5 & 0.003 \\
Low p53R2 mRNA ratio & 31 & 1 & \\
\hline
\end{tabular}

CRT, chemoradiation therapy; ESCC, esophageal squamous cell carcinoma. The low p53R2 mRNA ratio group $(<0.25)$ and high p53R2 mRNA ratio group $(>0.25)$ are shown. Complete response (CR) or partial response (PR) are considered effective cases, no change $(\mathrm{NC})$ or progressive disease $(\mathrm{PD})$ are considered ineffective cases.

that in the normal epithelium was 0.18 (95\% confidence interval:0.11-0.25), which were significantly different $(\mathrm{P}<0.05)$. Therefore, in the present study, the threshold was defined as 0.25 , based on the upper limit of the $95 \%$ confidence interval for the p53R2 mRNA ratio in the normal epithelium. According to the p53R2 mRNA ratio, patients were divided into a low $\mathrm{p} 53 \mathrm{R} 2 \mathrm{mRNA}$ ratio group $(<0.25)$ and a high p53R2 mRNA ratio group $(>0.25)$. CRT resulted in an effective response in 33 patients and ineffective response in 6 patients. Of the 33 patients for whom CRT was effective, 31 patients were in the low p53R2 mRNA index group. In contrast, 5 of the 6 patients for whom CRT was ineffective belonged to the high p53R2 mRNA index group. A low p53R2 mRNA index was significantly associated with CRT efficacy (Table I).

\section{Discussion}

p53 is the most frequently mutated tumor suppressor gene so far identified in human cancers, and the loss of p53 function is strongly associated with an increased risk of tumorigenesis
$(18,19)$. Many p53-inducible genes that can play a role in mediating the various downstream activities of p53 have been identified. Although the $\mathrm{p} 53$ product can activate the transcription of numerous downstream genes, it is still unclear how p53 can determine cell fates, such as cell cycle arrest, apoptosis, repair of damaged DNA, by the selection of target genes. Of these genes, p53R2 was recently identified as a novel RR gene, a small subunit 2 homologue, and is directly regulated by the wild-type $\mathrm{p} 53$ protein in the $\mathrm{G} 1$ and G2 phases of the cell cycle, supplying nucleotides for the repair of damaged DNA (5). In contrast, p53 mutants or p73, isoforms of the $\mathrm{p} 53$ family members, induce $\mathrm{p} 53 \mathrm{R} 2$ expression (20). Thus, p53R2 can be regulated by both p53-dependent and p53-independent pathways. In our previous study, the endogenous expression of the p53R2 protein in biopsy specimens taken by endoscopy prior to treatment was closely related to the poor response to CRT (3). In the present study, the p53R2 expression of 3 ESCC cell lines was enhanced in proportion to the endogenous expression following X-ray irradiation. In addition, the high expression of p53R2 was associated with poor radiosensitivity. Furthermore, we also found that the $\mathrm{p} 53 \mathrm{R} 2$ protein increases and changes its distribution from the cytoplasm to the nucleus following Xray irradiation, as previously reported (5). We found that the expression level of the $\mathrm{p} 53 \mathrm{R} 2$ protein is directly associated with radiosensitivity in ESCC. Therefore, we speculated that the direct knockdown of $\mathrm{p} 53 \mathrm{R} 2$ could improve the radiosensitivity of ESCC. In the present study, we successfully transfected p53R2 siRNA into esophageal cancer cell lines and knocked down the expression of the p53R2 mRNA and p53R2 protein, resulting in the improved radiosensitivity of a ESCC cell line following X-ray irradiation.

In order to examine the clinical impact of this study, we examined the relationship between the endogenous expression of p53R2 mRNA in tumor tissue from patients with ESCC and the response to CRT. A significant difference was observed between the high- and low-p53R2 mRNA expression groups with respect to radiosensitivity. CRT was effective in 31 of 32 
patients with low p53R2 mRNA and in only 2 of 7 patients with high p53R2 mRNA (Table I). Based on this analysis, low p53R2 mRNA expression cases could respond better to CRT than those with high p53R2 mRNA expression.

RNAi is the process of sequence-specific, post-transcriptional gene silencing in animals and plants, initiated by dsRNA that is homologous in sequence to the silenced gene (21-24). The effect of RNAi is considered to be an alternative to antisense DNA, since the effect of siRNA lasts longer than that of antisense DNA (23-25). In the present study, we started by knocking down p53R2 using antisense DNA. However, the results were poor and we therefore changed to siRNA transfection, with resultant success. An important technical issue now arises of how to deliver the siRNA to its effective position on the endogenous gene. Some examined delivery methods for siRNA have included using virus vectors, hydrodynamic delivery and cationic liposomes (2527), and Yano et al succeeded in establishing an siRNA delivery system using low toxicity cationic-liposome complexes in vivo (28).

In conclusion, we demonstrated that the knockdown of p53R2 using p53R2 siRNA improves radiosensitivity in ESCC, and that this concept has clinical value. Although an accurate delivery system of siRNA to target cells is yet to be established, we believe that this method is a good candidate for indicating CRT in p53R2-positive cases of ESCC.

\section{References}

1. Law S, Kwong DL, Kwok KF, Wong KH, Chu KM, Sham JS and Wong $\mathrm{J}$ : Improvement in treatment results and long-term survival of patients with esophageal cancer: impact of chemoradiation and change in treatment strategy. Ann Surg 238: 339-348, 2003.

2. Rosa AR, Gurski RR, Schirmer CC, Brentano L and Kruel CD: Survival and prognostic factors in patients with resected epidermoid oesophageal carcinoma. Int Surg 84: 193-198, 1999.

3. Okumura $H$, Natsugoe $S$, Matsumoto $M$, et al: The predictive value of p53, p53R2, and p21 for the effect of chemoradiation therapy on oesophageal squamous cell carcinoma. Br J Cancer 92: 284-289, 2005.

4. Takatori H, Natsugoe S, Okumura H, Matsumoto M, Ishigami S, Owaki T and Aikou T: Predictive value of COX-2 for the effect of chemoradiotherapy on esophageal squamous cell carcinoma. Oncol Rep 13: 697-701, 2005.

5. Tanaka H, Arakawa H, Yamaguchi T, et al: A ribonucleotide reductase gene involved in a p53-dependent cell-cycle checkpoint for DNA damage. Nature 404: 42-49, 2000.

6. Yamaguchi T, Matsuda K, Sagiya Y, Iwadate M, Fujino MA, Nakamura Y and Arakawa H: p53R2-dependent pathway for DNA synthesis in a p53-regulated cell cycle checkpoint. Cancer Res 61: 8256-8262, 2001.

7. Bernstein E, Caudy AA, Hammond SM and Hannon GJ: Role for a bidentate ribonuclease in the initiation step of RNA interference. Nature 409: 363-366, 2001.
8. Elbashir SM, Lendeckel W and Tuschl T: RNA interference is mediated by 21- and 22-nucleotide RNAs. Genes Dev 15: 188-200, 2001.

9. Hamilton AJ and Baulcombe DC: A species of small antisense RNA in posttranscriptional gene silencing in plants. Science 286: 950-952, 1999.

10. Hammond SM, Bernstein E, Beach D and Hannon GJ: An RNA-directed nuclease mediates post-transcriptional gene silencing in Drosophila cells. Nature 404: 293-296, 2000.

11. Zamore PD, Tuschl T, Sharp PA and Bartel DP: RNAi: doublestranded RNA directs the ATP-dependent cleavage of mRNA at 21 to 23 nucleotide intervals. Cell 101: 25-33, 2000.

12. Dorsett $Y$ and Tuschl T: siRNAs: applications in functional genomics and potential as therapeutics. Nat Rev Drug Discov 3: 318-329, 2004.

13. Lieberman J, Song E, Lee SK and Shankar P: Interfering with disease: opportunities and roadblocks to harnessing RNA interference. Trends Mol Med 9: 397-403, 2003.

14. Sobin LH and Fleming ID: Union Internationale Contre le Cancer and the American Joint Committee on Cancer. TNM Classification of Malignant Tumors. 5th edition. Cancer 80: 1803-1804, 1997.

15. Japanese Society for Esophageal Diseases: Guide Lines for the Clinical and Pathologic Studies on Carcinoma of the Esophagus. 9th edition. Kanehara \& Co., Ltd., Tokyo, 1999.

16. Barnas C, Martel-Planche G, Furukawa Y, Hollstein M, Montesano $\mathrm{R}$ and Hainaut $\mathrm{P}$ : Inactivation of the p53 protein in cell lines derived from human esophageal cancers. Int J Cancer 71: 79-87, 1997

17. Itoshima $\mathrm{T}, \mathrm{Fujiwara} \mathrm{T}, \mathrm{Waku} \mathrm{T}$, et al: Induction of apoptosis in human esophageal cancer cells by sequential transfer of the wildtype p53 and E2F-1 genes: involvement of p53 accumulation via ARF-mediated MDM2 down-regulation. Clin Cancer Res 6: 2851-2859, 2000

18. Hollstein M, Sidransky D, Vogelstein B and Harris CC: p53 mutations in human cancers. Science 253: 49-53, 1991

19. Levine AJ: The tumor suppressor genes. Annu Rev Biochem 62: 623-651, 1993.

20. Nakano K, Balint E, Ashcroft M and Vousden KH: A ribonucleotide reductase gene is a transcriptional target of p53 and p73. Oncogene 19: 4283-4289, 2000.

21. Fire A: RNA-triggered gene silencing. Trends Genet 15: 358-363, 1999.

22. Hammond SM, Caudy AA and Hannon GJ: Post-transcriptional gene silencing by double-stranded RNA. Nat Rev Genet 2: 110-119, 2001 .

23. Sharp PA: RNA interference. Genes Dev 15: 485-490, 2001.

24. Tuschl T: RNA interference and small interfering RNAs. Chembiochem 2: 239-245, 2001.

25. Song E, Lee SK, Wang J, et al: RNA interference targeting Fas protects mice from fulminant hepatitis. Nat Med 9: 347-351, 2003.

26. Shen C, Buck AK, Liu X, Winkler M and Reske SN: Gene silencing by adenovirus-delivered siRNA. FEBS Lett 539: 111-114, 2003.

27. Sioud M and Sorensen DR: Cationic liposome-mediated delivery of siRNAs in adult mice. Biochem Biophys Res Commun 312: 1220-1225, 2003.

28. Yano J, Hirabayashi K, Nakagawa S, et al: Antitumor activity of small interfering RNA/cationic liposome complex in mouse models of cancer. Clin Cancer Res 10: 7721-7726, 2004. 